\title{
Blended Training Model with Knowledge Management and Action Learning Principles to Develop Training Program Design Competencies
}

\author{
Pattama Chandavimol, Onjaree Natakuatoong, and Pornsook Tantrarungroj
}

\begin{abstract}
The objective of this research is to develop a blended training model by applying the knowledge management and action learning principles, to further develop the training program design competencies of personnel development staff in government sectors. The research method was divided into three phases. The first phase was to study the research papers, and literature under the context of blended training, knowledge management, action learning and competency in training design. The second phase was to explore the situation problems and needs of personnel development staff in regards to the design of training programs. The third phase was to design the blended training programs by using the knowledge management principles and action learning to improve the training program design competency. The research findings show the challenges caused by inadequate knowledge in blended training, knowledge management, action learning as well as insufficient time allocated by the management team and personnel development staff towards the subject. Even though development practitioners today use various technologies in learning and managing knowledge at a high level, there still remains a need for the creation of a community of practice, and the appraisal and recognition of successful practitioners, together with a knowledge map that is easy to search and utilize. Those can be applied in training model development.
\end{abstract}

Index Terms-Action learning, blended training, knowledge management, training program design competencies.

\section{INTRODUCTION}

The Civil Service Act, B. E. 2551 [1] has stipulated that the government sectors need to transform the working approach and apply core competencies and integrity to their working style. The Act recognizes the importance of having effective government officers and management system development; therefore the personnel development staffs must have professional-level training. Firstly, they must be capable of creating good training programs. Competency can be defined as a group of knowledge, skills and attributes that are correlated with positive results in a particular work position; it can be compared to a well-accepted standard and can be developed through training programs [2].

However, most of the training programs still use traditional techniques, which cannot show clearly how much better the trainees can improve their competencies as desired,

Manuscript received April 10, 2013; revised July 20, 2013

The authors are with the Department of Educational Technology and Communications, Faculty of Education, Chulalongkorn University, Thailand (e-mail: pattama.chandavimol@gmail.com, onjaree.n@chula.ac.th, pornsook.t@chula.ac.th). nor how well they can apply what they have learned to their jobs. The current training programs still do not adequately promote learning from job experience, and do not place enough value on that type of experience. The studies and related research demonstrates that experience and opinion exchanges lead to learning and problem-solving co-operation along the knowledge management process. For that reason, the development of an efficient training model is urgently needed.

Today, new technologies have become a part of daily life and can be deployed in training programs. We have witnessed the e-Learning platform, questions posted on web boards or via email as well as learning management systems used by learners to follow up on lectures. Both in-classroom and electronic learning types give different benefits to learners. Therefore, we should consider only the benefits of designing blended training programs. Blended learning is an integration of evolving technological advancements. The combination of online learning with the interaction and participation offered in the best of traditional learning are the key strategy in learning and creating better learning [3]. The blended training pattern should consist of trainees, contents, technologies, and infrastructure. The learning types should be both face-to-face and e-Learning, both synchronous and asynchronous [4].

In the era of knowledge-based society, the learning mechanism in 21st century has changed; $30 \%$ of knowledge is from training; whereas $70 \%$ is from work experience and exchanging experiences. The United States Department of Labor shows similar figures: $30 \%$ of knowledge is gained from systematic learning from training and education, and the other $70 \%$ from work experience. Knowledge is held by each person, and people cannot communicate all of the knowledge that they have; therefore, it is important to design the knowledge management process to bring out the tacit knowledge held by each worker to maximize the transfer of this knowledge. It can be in the form of activities led by the community of practice, with communication and technology designed to search, build, store, share, and use the knowledge and priceless experience to maximize the benefits to the corporation [5]. The information must be stored electronically and always available in such a knowledge base so everyone in the corporation can make use of it. This "always available" knowledge base approach is a useful tool. It can transfer expert knowledge immediately, and accumulate more expert knowledge. The knowledge is generated from the well-trained staff in the organization. Once the knowledge is retrieved to use and transferred from 
one expert to another, it will be updated continuously and becomes a valuable knowledge development.

The training design requires that the practices be adjusted to the changes in the organization. The training designers must always be capable of managing and being flexible to those changes [6]. The action learning can be developed from experience and knowledge, together with the individual skills and group skills, which are applied to audit difficult tasks or to solve the organization's specific problems. In addition, web-based learning or e-learning might be useful tools to facilitate action learning in teams and to compensate for the lack of factual learning. Good e-learning is very useful for factual learning [7]. "Reference [8] utilizes action learning as a way to build up the knowledge management system using four approaches:

1) Knowledge source - the action learning should realize the organization's resources, the facilities available to it for exchanging and sharing the framework.

2) Knowledge creation - personnel should find new solutions to solve old problems and replace obsolete knowledge. The members should create new knowledge and promote innovation in the group. "Reference [9] suggests that information creation is a basic requirement for an organization to be able to continuously renew itself. Knowledge creation leads to the formation of a self-organizing group."

3) Knowledge storage - the organization should classify the information to be stored, develop a categorization system, and maintain the knowledge value through continuous learning interaction and reflection on what one has learned.

4) Knowledge transfer and utilization - the group members should identify and store the knowledge that they need to turn themselves into experts. The learning group will define the approach with which the members can transfer the knowledge and wisdom gained from the activity of solving problems to the rest of their society."

The next important step is to integrate the key elements of training, action learning, experience and practices together, to facilitate the learning process. The experts then need to design the contents to be flexible and easy to access, in a learner-centric approach; the most popular method is via web site [10]. The learners can improve to their highest level of capability when the personnel development staff is highly competent in designing the trainings, bringing the right technologies together to design and manage the blended training.

It is clearly seen that by bringing knowledge management and action learning into the training process, the trainees can gain new knowledge, develop skills from knowledge and experience sharing with other trainees and the teaching experts, and can apply them to work effectively. Researchers will bring this approach of knowledge management combined with action learning to blend into the traditional classroom and e-learning techniques. Meeting the online experts can render the maximum benefits of their experience, learning and blended training to learners.

Seeing that the personnel development staff plays a key role in developing new initiatives, the researchers then creates a blended training model by using knowledge management and action learning to develop the personnel development staff.

\section{The PuRPose OF THE RESEARCH}

The objectives of this research are:

1) To study the papers, research and literature in the context of blended training, knowledge management, action learning and competency in training design.

2) To study the situation and problems faced by personnel development staff in regards to the design of blended training, by applying questionnaires to survey about blended training, knowledge management and action learning principles.

3) To propose the blended training model by using the knowledge management and action learning principles to develop the training program design competencies.

\section{RESEARCH METHODOLOGY}

There are three phases of this study:

Phase 1 Study the papers, research and literature under the context of blended training, knowledge management, action learning and competency in training design.

Phase 2 Explore the situation, problems, and needs of personnel development staff in regards to the design of blended training, by applying the knowledge management and action learning principles.

Phase 3 Design the blended training programs $w$ the knowledge management principles and action learning to improve the training program design competency.

\section{A. Population and Sample Size}

The population in this research is the personnel development staff in government units, responsible for training design, management, and project development. The population will be limited to those having more than two years of experience in a training job in these government units.

The exact number of sample size is uncertain since the government has not collected statistics about its development staff based on these criteria. Rather the group as a whole is simply classified as Human Development staff. For that reason, the researcher applies the sample size from uncertain population model of [11] at $95 \%$ confidence result $(0.05$ level). From the reference table, the sample size shall be 400 persons.

\section{B. Tools and Developing Tools in the Survey}

The researcher has developed a questionnaire as a survey tool. The tool development process is as follows:

1) Study the papers, research and literature under the context of blended training, knowledge management, action learning and competency in training design, and apply them as a framework for tool development.

2) Study and synthesize the contents of blended training by applying the questionnaires used to survey knowledge management and action learning principles, and put together the checklist and open-ended questions regarding the past theory and research.

3) Bring the questionnaire which is designed to study the 
situation problems and needs of personnel development staff in regards to the design of blended training to the advisory professor to check the properness and completeness.

4) Check the content validity by one training expert, one knowledge management expert and one action learning expert. Bring the comments to improve the questionnaire.

5) Check the reliability and understanding of the survey tool by testing the questions with 30 responders who have a similar profile as the targeted survey population.

6) Improve the questionnaire by applying knowledge management, action learning, testing follow up and re-applying to the survey.

7) The researcher took 45 days to gather the data.

8) The researcher followed up with the responders from the sampling group and collected 261 completed questionnaires by herself, which represented $65.25 \%$ of the sample set.

9) The researcher analyzed the data to explain the situation and problems of the blended training programs by using the knowledge management and action learning principles.

\section{Findings}

The key findings from the sampling government unit group follow. $93.9 \%$ of the staff has access to learning technology, $91.2 \%$ have experience in action learning, $90.4 \%$ have a knowledge management plan, and $89.3 \%$ have a training program which is designed to use flexible and blended training.

Only $28.3 \%$ had the training objectives shared with them before the training sessions. $30 \%$ admitted that they selected the problems in the organization to be the training topics. $22.5 \%$ implement the post-training evaluation for further training development. $25.6 \%$ said that the most popular access tool to training provided by the organization is email. $13.5 \%$ have advisory discussions with experts on particular topics to improve their knowledge. $24.6 \%$ agree that the group of experts in a successful organization exchange opinions. $49.1 \%$ were in consensus that the most convenient tool for employees in the organization to search for knowledge is a knowledge-based platform.

The sample group shared the opinion that the major problem is the lack of education among the management team and personnel development staff in the area of knowledge management, action learning and blended training strategies. Many of the trainees do not know how to use modern technologies and do not have sufficient time allocated for training and development.

The personnel development staff does not see, nor accept new methods and technology for knowledge management and action learning.

The communication channels are not enough. The communication activities through the existing channels, i.e. web site, intranet, brochure and venue, are not sufficient.

\section{Suggestions}

Encourage the personnel development staff to learn more. The staff should study the principles and techniques of efficient training; and be capable of applying the knowledge to real practices. The staff should divide the whole process into steps, documenting it in the form of an operational manual of blended training, knowledge development and action learning.

Educate the learners of knowledge management and action learning via electronic communication channels.

\section{RESEARCH RESULTS}

From the key research findings in both phases, the researcher had synthesized the components and the stages of a blended training model with knowledge management and action learning principles to develop training program design competency (see Fig. 1).

The model consisted of seven components:

1) Personnel - including lecturers, learners, facilitators who are responsible for coordinating, stimulating, creating the atmosphere, and helping with communication.

2) Community of Practice -5-8 attendees in each group. They may come from the same working units or share common interests in particular subjects. They may join the group voluntarily or by assignment; to solve some problems.

3) Content - online/offline content.

4) Problems -They should be real problems that their organization is facing that need solutions.

5) Information technology - This includes:

- The Learning management system, serving as a management center, utilizing Internet tools to collaborate with lecturers-learners, learners-learners and learners- knowledge database.

- Interactive communications including email, web boards, chat, discussion boards and web blogs should also be provided.

- The knowledge management system, which refers to a full range of Internet, intranet, knowledge storage, e-learning course, e-book, knowledge map, and electronic document tools, as well as discussions with experts.

6) Measurement - which includes:

- Evaluation of projects before and after the training by the expert.

- Evaluation of training design competency before between and after the blended training.

- The assessment of activity participation such as the timely submission of assignments, frequency of online class participation, frequency in noting down knowledge gained in a personal blog and group blog, as well as the frequency of expressing opinions and participating in online debate.

7) Rewards and recognition. These will be good stimuli, drivers and enhancements for a training project to achieve the objectives and encourage participation.

The three phases, with eight stages in six weeks of the blended training model are:

Phase 1 in the First week: Introduction to blended training. In this period, the lecturers inform the learners about the objectives of the training, scope of the content, results expected, and duration of the training. The lecturer will 
explain any important context that the learners should know before beginning the blended training, how to use the technology, any supportive information, and other useful suggestions.



Fig. 1. Blended training model with knowledge management and action learning.

Stage 1 covers the preparation of the personnel development staff. This period is used to explain the activity objectives, procedures, project assessment, technology application and demonstration, knowledge management method, and to evaluate the competency of the learners before the training.

Stage 2 covers the identification of problem points, knowledge desired, set up of the community of practice's group (each group has 5-8 members), problem analysis among the group, and record the problems in a blog.

Stage 3 is when the knowledge experience and opinions about the problems are exchanged. Learners can propose the solutions to problems and record them in a blog.

Phase 2 is the second week to the fifth week: the proposal of contents and problems.

Stage 4 is the knowledge acquisition stage. This involves the ways that the learners can search for new information by accessing online courses, searching the Internet, exchanging information learned, brainstorming, discussing with experts, and then recording this information in a blog.

Stage 5 is to build up a knowledge base. This happens when the learners discuss how to finalize the problem solutions, synthesize all recommendations, improve the project, record this information, sharing the solutions with other groups, and listening to other groups' opinions.

Stage 6 is designed to bring the project to work. It is the trial in a real work environment. The learners record their findings, exchange opinions, assess, recommend, and summarize the new knowledge that they have learned in their own blogs. They also improve on the training from the action learning.

Stage 7 is to store their own and their group's knowledge. The researcher will recommend an online method to do this. The learners can retrieve such knowledge, and search for new knowledge from other groups' records.

Phase 3 is the last week: the sixth week: Summary.

Stage 8 is the final process, when the trainees propose the paper to the Committee. The researcher summarizes the project assessment, program participation, appraisal and rewarding activity, promotes the paper, and assesses the training design competency after the training.

\section{CONCLUSION}

A trial blended training model should be implemented in some courses, to elaborate the importance and promote other channels of learning such as the use of web sites.

In planning a training course, the staff should give key consideration to the target audience then create the appropriate content and training process as well as provide a proper case study to meet the audience's profile.

\section{ACKNOWLEDGMENT}

This work was supported in part by the 90th Anniversary of Chulalongkorn University Fund (Ratchadaphiseksomphot Endowment Fund).

\section{REFERENCES}

[1] Office of the Civil Service Commission. (March 2009). Civil Service ACT, B.E. 2551. [Online] pp. 3-4. Available: http://www.ocsc.go.th/ocsc/th/uploads/File/ART\%20CIVIL.pdf

[2] S. B. Parry, "Evaluating the impact of training: A collection of tools and techniques," VA: American Society for Training and Development, 1997, Alexandria, ch. 3, pp. 23-24.

[3] K. Thorne, Blended learning: How to integrate online and traditional learning, Kogan Page Ltd., 2003, pp. 16.

[4] H. Singh and C. Reed. (March 2001). A white paper: Achieving success with blended learning. ASTD State of the Industry Report. American Society for Training and Development, Centra Software. 
[Online] pp. 2-3. Available: http://facilitateadultlearning.pbworks.com/f/blendedlearning.pdf

[5] T. H. Davenport and L. Prusak, Working knowledge: how organizations manage what they know, Boston, Mass: Harvard Business School Press, 2000. ch. 1, pp. 11-12.

[6] R. C. Richey, D. C. Fields, and M. Foxon, "Instructional design competencies: The standards," in N. Y. Syracuse, Eric Clearinghouse on Information Technology, 3rd ed., 2001, ch. 1, pp. 29.

[7] T. Ivergard, Action learning: Some principles and practicalities, Bangkok: Civil Service Training Institute, 2002, pp.57-58.

[8] M. J. Marquardt, Action learning in action: transforming problems and people for world-class organizational learning, Palo Alto, Calif: Davies-Black, 1999.

[9] I. Nonaka and H. Takeuchi, The knowledge-creating company, New York: Oxford University Press, 1995.

[10] M. E. Echols. (August 2010). An informal debate: Bridging the gap between formal and informal learning. Chief Learning Officer. [Online] pp. $10 . \quad$ Available: https://humancapitalmedia.site-ym.com/store/view_product.asp?id=10 95537\&hhSearchTerms=August + and +2010

[11] T. Yamane, Statistics: An introductory analysis, New York: Harper and Row Publication, 1973, pp. 886.

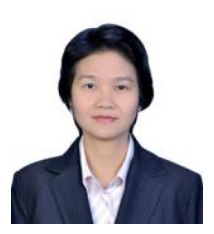

Pattama Chandavimol was born in Bangkok, Thailand on November 26, 1968. The author received her bachelor's degree in education, majoring in non-formal education and audio-visual communications in 1990, and a master's degree in the field of educational technology and communications from Chulalongkorn University, Thailand in 2001. She has been involved in human development activities and learning environments development since her first job at Samart Telcoms PCL., a leading satellite communication service provider in Thailand. Since then, she has been passionate about the power of modern education when applying various new technologies towards human-being development. In 2008, she decided to pursue her education in a $\mathrm{Ph} . \mathrm{D}$. program in educational technology and communications at Faculty of Education, at the same institute. She has completed all coursework and is now a Ph.D. candidate. She is currently holding the position of e-Learning and Knowledge Management Manager, Learning and Development Division at Siam Commercial Bank PCL., in Thailand.

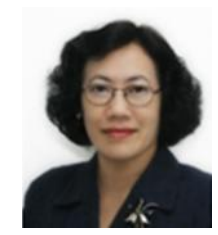

Onjaree Natakuatoong received the M.E.d. from Chulalongkorn University, Bangkok, Thailand and the Ph.D. degree from University of Iowa, Iowa City, IA U.S.A., in 1986. The major field of study is Instructional Design and Technology. Dr. Natakuatoong is an Associate Professor at Educational Technology and Communications Department and Director of Research and Development Center on Knowledge Management, Faculty of Education, Chulalongkorn University, Thailand. Her fields of research include Educational Technology, Instructional Design, Human Resource Development, Knowledge Management, and Learning Organization. She is a former President of Thailand Society for Training and Development and a member of The Association for Education Communications and Technology of Thailand

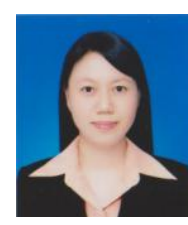

Pornsook Tantrarungroj is a lecturer in the Department of Educational Technology and Communications, Faculty of Education, Chulalongkorn University, Thailand. She received her Ph.D. degree from Indiana State University in 2008. Her academic background is in Curriculum and Instruction with an emphasis in Educational Technology. She has extensive knowledge of computer applications, website and multimedia design, and system analysis. Her research interests are teaching and learning style, multimedia integration, and instructional strategy which include the development and improvement of various multimedia production systems in both face-to-face and online learning environments. 